\title{
Bibliometrics Analysis for Rough Set Field Research in China
}

\author{
Yuanren $\mathrm{Wu}^{1,2, \mathrm{a}}$, Shuyan $\mathrm{Li}^{1,2, \mathrm{~b},{ }^{*}}$ \\ ${ }^{1}$ TSL School of Business \& Information Technology, Quanzhou Normal University, Quanzhou \\ 362000, China; ${ }^{2}$ High Educational Engineering Research Center of Fujian Province for E-Commerce \\ Intelligent Based on Cloud Computing and IOT \\ ayuanrenwu@126.com; 'shuyanlee@126.com
}

\begin{abstract}
Based on 6091 papers for rough set field collected by critical journals and CSSCI in China Knowledge Internet (CNKI) from 2000 to 2016, analysis are made by bibliometrics. Citespace Software is applied. Quantity of issuing, key words, issuing authors and issuing authorizations for rough set research field in China are systematically reviewed and summarized in the article. Some characteristics on rough set research field in China are gained to supply reference and information to relative scholars for subsequent researches.
\end{abstract}

Keywords: Rough set, bibliometrics, characteristic.

\section{Introduction}

Rough Set Theory is put forward by Professor Pawlak in 1982, which is a mathematics tool ${ }^{\text {[1] }}$ for quantitative analysis and treatment of inaccurate, inconsistent and uncompleted information and knowledge. Due to new concept and unique method, rough set theory has become an important treatment technology for intelligent information ${ }^{[2][3][4]}$. The theory has been applied in kinds of fields, such as learning by machine \& knowledge discovery, data explore, and support \& analysis of determination. The journals related to research of rough set are numerous, so as to the one of results. There have been lots of scholars researching for rough set from different views, e.g., Li Huaxiong (in 2010 $)^{[5]}$, comprehensive retrospection of determination and development brief for rough set, Tang Jianguo (2010) ${ }^{[6]}$, description on combination of rough set and other soft calculation theories, Yang Chuanjian (2012) ${ }^{[7]}$, focus on simple attribute for classical rough set theory and description in three aspects, Wang Xueen (2013) ${ }^{[8]}$, research \& introduction of basic theory and expansion model of rough set, especially in accuracy changing, allowance, advantage and vague, and Qiu Guofang (2014) ${ }^{[9]}$, depending on research of Lattice Concept, introduction of research and development of application in two aspects including characteristic selection and mode classification.

The above mentioned is systematical summarization and review of rough set research, which indicates a direction for development and research of rough set in China as a promotion of research. However, these comprehensive articles are just result summarizations made by the authors in certain respects with obvious one-sidedness and subjectivity so that lots of research results for rough set in China for resent years can' t be reviewed in general, which probably causes deviation. After search, it is found that there is no analysis on literature for rough set research in advantage of existing bibliometrics, but bibliometrics often discovers general condition, contents and characteristic of research for certain one course or field. There has been plenty of analysis on so many courses and fields through bibliometrics, such as quantitative economics (Wu Yuanren \& Shen Lisheng, 2015) ${ }^{[10]}$. Therefore, the existing literatures are generally reviewed and summarized by the article, and research status is mastered in order to provide reference for rough set research.

\section{Data Source and Research Method}

Data in the article is derived from critical journals and CSSCI related to rough set source collected in database of CNKI , that is, on advanced search page of journal in CNKI, accurate search is made on Jan. 10, 2017 through word "rough set" in the search title for years of 2000 to 2016. 6193 literatures in the journals on rough set research field in China are available. 6091 effective articles are 
gained after deduction of relative solicits contributions, introductory remarks and conference promotions, which are used in this article with key words, authors and issuing authorities. From lots of bibliometrics, corresponding data is gained with application of Citespace Software, which is further analyzed.

\section{Empirical Analysis}

\subsection{Quantity and Trend of Issued Paper}

Annual quantity and distribution condition of issued papers for rough set research field are shown in Fig. 1. It indicates that issued papers have been increasing since 2000 to 2010. In 2010, 588 papers are issued in peak. Decrease happens in following years. During 2013 to 2016, about 360 papers are basically maintained.

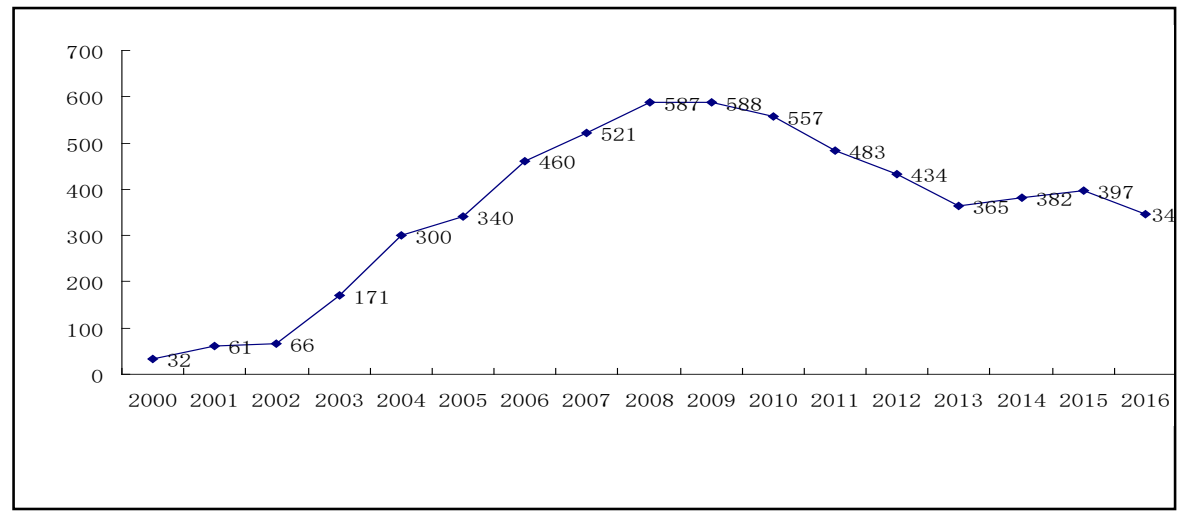

Fig. 1 Quantity of Issued Papers for Rough Set Research Field in China

\subsection{Main Issued Journals for Rough Set}

It is found in statistic that more than 50 papers (in Table1) for rough set research field in China during 2000 to 2016 are issued in 20 kinds of academic journals, in which "Computer Engineering and Application" dominates, and "Computer Science", "Computer Engineering", "Computer Application", "Vague System and Mathematics" , "Computer Engineering and Design" "Research on Computer Application", "Control and Determination", "Minor \& Micro Computer Systems" \& "Statistic and Determination" are secondary, totally more than 100. Except "Vague System and Mathematics" and "Statistic and Determination", the others are journals on computer field, which shows rough set dominates in application and research of computer field.

Table 1 Main Issued Journals for Rough Set Research Field in China

\begin{tabular}{|c|l|c|lc|}
\hline Frequency & \multicolumn{1}{|c|}{ Issued Journal } & Frequency & \multicolumn{2}{|c|}{ Issued Journal } \\
\hline 550 & $\begin{array}{l}\text { Computer Engineering and } \\
\text { Application }\end{array}$ & 66 & $\begin{array}{l}\text { System Engineering and Electronic } \\
\text { Technology }\end{array}$ & Electronic \\
\hline 340 & Computer Science & 57 & $\begin{array}{l}\text { System Engineering and } \\
\text { Technology }\end{array}$ \\
\hline 197 & Computer Engineering & 56 & $\begin{array}{l}\text { Theory and Practice of System Engineering } \\
\text { Intelligence }\end{array}$ \\
\hline 144 & Computer Application & 55 & Integrated Fabrication System for Computer \\
\hline 139 & Vague System and Mathematics & 55 & Theory and Practice of System Engineering \\
\hline 135 & Computer Engineering and Design & 55 & Microelectronics and Computer \\
\hline 117 & Research on Computer Application & 54 & Integrated Fabrication System for Computer \\
\hline 115 & Control and Determination & Minor \& Micro Computer Systems & 53 & Practice and Understand of Mathematics \\
\hline 100 & Statistic and Determination & 51 & Journal of Shandong University \\
\hline
\end{tabular}




\subsection{Frequently Used Key Words}

Key words are usually extracted by author for the article contents. Frequently used key words and center of media for rough set research are achieved through Citespace Software in downloaded 6091 papers in this section. Center of media means linkage function for certain node in the net and all nodes. Bigger center of media of key word will have effect on capacity of other key words appearing in an article simultaneously. 27 frequently used key words or the ones with high center of media for rough set research field from 2000 to 2016 are displayed in Table2.

Table 2 Frequently Used Key Words for Rough Set Research Field in China

\begin{tabular}{|c|c|l|c|c|l|}
\hline Quantity & $\begin{array}{c}\text { Center } \\
\text { of media }\end{array}$ & \multicolumn{1}{c|}{ Key Words } & Quantity & $\begin{array}{c}\text { Center } \\
\text { of media }\end{array}$ & \multicolumn{1}{|c|}{ Key Words } \\
\hline 3944 & 0.87 & rough group & 106 & 0.08 & tree for determination \\
\hline 967 & 0.66 & simple attribute & 106 & 0.01 & discretization \\
\hline 469 & 0.11 & rough group theory & 102 & 0.03 & knowledge reduction \\
\hline 461 & 0.06 & troubleshooting & 94 & 0.03 & rule for determination \\
\hline 325 & 0.09 & data explore & 94 & 0.02 & information system \\
\hline 232 & 0.03 & neural network & 89 & 0.11 & advantage relationship \\
\hline 199 & 0.05 & supportive vector machine & 81 & 0.07 & difference matrix \\
\hline 192 & 0.04 & sheet for determination & 81 & 0.1 & granular computing \\
\hline 167 & 0.03 & heredity computing & 70 & 0.09 & feature selection \\
\hline 166 & 0.18 & accuracy-changing rough group & 59 & 0.06 & rule extraction \\
\hline 149 & 0.17 & fuzzy rough set & 44 & 0.1 & approximation operator \\
\hline 148 & 0.2 & vague group & 39 & 0.04 & knowledge acquisition \\
\hline 144 & 0.11 & Information entropy & 29 & 0.09 & soft computing \\
\hline 143 & 0.21 & uncompleted information system & & & \\
\hline
\end{tabular}

Viewing from Table2, the key words with high center of media are rough group, simple attribute, uncompleted information system, vague group, accuracy-changing rough group, fuzzy rough set, rough group theory, information entropy, advantage relationship, granular computing, and approximation operator. Center of media for these key words reaches or surpasses 0.1 , representative research contents of which have been most fields or directions for rough set since resent 17 years. Meanwhile, many calculation models involved in computer technology are found in these frequently used key words, such as simple attribute, data explore, neural network, supportive vector machine, heredity computing, and sheet, tree \& rule for determination.

\subsection{Analysis on Author and Authority}

With analysis and statistic of the author for rough set research in China, the authors with largest quantity articles by 6091 (not less than 20 issued articles) are shown in Table 3.Viewing from Table 3, top three authors are Xu Zhangyan, Miao Duoqian and Qin Keyun, with more than 50 issued articles. There are 30 authors with not less than 20 issued articles. All of them are the scholars with top largest quantity articles for rough set research in China during 2000 to 2016. 
Table3 Author with Top Largest Quantity Articles for Rough Set Research Field in China

\begin{tabular}{|c|c|c|c|c|c|}
\hline Quantity & Author & Quantity & Author & Quantity & Author \\
\hline 74 & Xu Zhangyan & 32 & Liang Jiye & 24 & Xu Weihua \\
\hline 70 & Miao Duoqian & 30 & Wang Jiayang & 23 & Zhu Haodong \\
\hline 54 & Qin Keyun & 29 & Jiang Yun & 23 & Yang Jingyu \\
\hline 47 & Yang Bingru & 28 & Yang Chuanjian & 23 & Shu Lan \\
\hline 46 & Wang Guoyin & 28 & Mou Zhiwen & 22 & Zhang Qinghua \\
\hline 44 & Li Longshu & 27 & Yan Deqin & 22 & Li Tianrui \\
\hline 43 & Yang Xibei & 26 & Zhang Xianyong & 22 & Zhu Feng \\
\hline 42 & Zhang Wenxiu & 26 & Li Jinjin & 21 & Zhou Xianzhong \\
\hline 40 & Xu Jiucheng & 26 & Mi Jusheng & 21 & Huang Bing \\
\hline 36 & Lv Yuejin & 25 & Ge Hao & 20 & Qian Yuhua \\
\hline
\end{tabular}

With analysis and statistic of the author for rough set research in China, there are 22 issuing authorities for rough set research in China with quantity of issued articles (not less than 24) .Viewing It obviously indicates that both Computer and Information Technology Department of Shanxi University and Information Engineering Department of Science \& Technology University Beijing are top authorities with 59 issued articles. In additional, top five authorities with largest quantity articles are consisted of Information Science \& Technology Department of Southwest Jiaotong University, Information Science \& Engineering Department of Central South University and Computer Science \& Technology Department of Tongji University, in total of more than 50 issued articles.

\section{Conclusions}

Some characteristics for rough set research in China are gained analyzed through bibliometrics based on the key words, authors and issuing authorities mentioned in 6901 papers issued in journals. The research indicates that rough set donates in research and application of computer field. Research contents represented by rough group, simple attribute, uncompleted information system, vague group, accuracy-changing rough group, rough group theory, information team, advantage relationship, granular computing, and approximation operator, are most fields or directions for rough set since resent 17 years. Xu Zhangyan, Miao Duoqian and Qin Keyun are top three authors with largest quantity articles in China. Besides, Computer and Information Technology Department of Shanxi University, Information Engineering Department of University of Science \& Technology Beijing, Information Science \& Technology Department of Southwest Jiaotong University, Information Science \& Engineering Department of Central South University and Computer Science \& Technology Department of Tongji University are top five authorities.

\section{Acknowledgments}

This work was financially supported by the Social Science Planning Project of Fujian Province (Grant NO. FJ2016B106). Corresponding author is Shuyan Li. E-mail: shuyanlee@126.com

\section{References}

[1]Pawlak Z, Rough set, International Journal of Computer and Information Sciences, 1982,pp.341-356.

[2]Chan C C, Grzymala Busse J W, Ziarko W P, Rough sets and current trends in computing, //Proceedings of the 6th International Conference, RSCTC 2008. Akron, Ohio, USA,2008. 
[3]An A, Stefanowski J, Ramanna S, Butz C J, Pedrycz W,Wang G Y et al. , Rough sets, fuzzy sets, data mining and granular computing, //Proceedings of the 11th International Conference, RSFDGrC 2007. Toronto, Canada, 2007.

[4]Wang G Y, Li T R, Grzymala-Busse J, Miao D Q, Skowron A, Yao Y Y, Rough sets and knowledge technology,//Pro-ceedings of the RSKT 2008. Chengdu, China, 2008.

[5]Li H X,Liu D, Zhou X Z, A Survey of the Combination of Rough Set and Other Soft Computing[J]. A Survey of Decision Rough Set Model, Journal of Chongqing University of Posts and Telecommunications (Natural Science Edition) 2010,pp.624-630 .

[6]Tang J G, Zhu F, She K, et al. ,A Survey of the Combination of Rough Set and Other Soft Computing, Journal of Computer Applications, 2010,pp.2404-2410.

[7]Yang C J, Ge H, Wang Z S, A Survey of Attribute Reduction Methods Based on Rough Set, Journal of Computer Applications, 2012,pp.16-20.

[8]Wang X E,Han C Z,Han D Q,et.al. , Rough Set Research Review,Journal of Control Engineering,2013,pp.1-8.

[9]Qiu G F, Zhang Z X,Zhang W, A Survey of Concept Lattice Theory Based on Rough Set Method,Journal of Fuzzy Systems and Mathematics, 2014,pp.168-177.

[10]Wu Y R and Shen L S,A Study on Knowledge Map of Quantitative Economics in China: Bibliometric Analysis Based on CSSCI (2000-2014), Data Economic Dynamics,2015,pp. 84-96. 